\title{
AIAA-95-3457
}

\section{Ground-to-Flight Handling Qualities Comparisons for a High Performance Airplane}

\section{Jay M. Brandon, Louis J. Glaab, Philip W. Brown, \& Michael R. Phillips NASA Langley Research Center Hampton, VA 23681-0001}

\section{Atmospheric Flight Mechanics Conference}

\author{
August 7-9, 1995/ Baltimore, Maryland
}

For permission to copy or republish, contact the American Institute of Aeronautics and Astronautics 370 L'Enfant Promenade, S.W., Washington, D.C. 20024 



\title{
GROUND-TO-FLIGHT HANDLING QUALITIES COMPARISONS FOR A HIGH PERFORMANCE AIRPLANE
}

\author{
Brandon, Jay, M., Glaab*, Louis, J., \\ Brown, Philip, W, and Phillips, Michael, R. \\ NASA Langley Research Center \\ Hampton, VA 23681 \\ *Lockheed Engineering and Sciences Company \\ Hampton, VA
}

\begin{abstract}
A flight test program was conducted in conjunction with a ground-based piloted simulation study to enable a comparison of handling qualities ratings for a variety of maneuvers between flight and simulation of a modem high performance airplane. Specific objectives included an evaluation of pilot-induced oscillation (PIO) tendencies and a determination of maneuver types which result in either good or poor ground-to-flight pilot handling qualities ratings.

A General Dynamics F-16XL aircraft was used for the flight evaluations, and the NASA Langley Differential Maneuvering Simulator was employed for the ground based evaluations. Two NASA research pilots evaluated both the airplane and simulator characteristics using tasks developed in the simulator. Simulator and flight tests were all conducted within approximately a one month time frame.

Maneuvers included numerous fine tracking evaluations at various angles of attack, load factors and speed ranges, gross acquisitions involving longitudinal and lateral maneuvering, roll angle captures, and an ILS task with a sidestep to landing. Overall results showed generally good correlation between ground and flight for PIO tendencies and general handling qualities comments. Differences in pilot technique used in simulator evaluations and effects of airplane accelerations and motions are illustrated.
\end{abstract}

\section{NOMENCLATURE}

$\begin{array}{ll}\mathrm{g} & \text { normalized acceleration } \\ \mathrm{p} & \text { roll rate, } \mathrm{deg} / \mathrm{sec} \\ \dot{\mathrm{p}} & \text { roll rate acceleration, } \mathrm{deg} / \mathrm{sec}^{2} \\ \mathrm{q} & \text { pitch rate, } \mathrm{deg} / \mathrm{sec} \\ \mathrm{r} & \text { yaw rate, } \mathrm{deg} / \mathrm{sec} \\ \alpha & \text { angle of attack, deg }\end{array}$

$\begin{array}{ll}\theta & \text { pitch angle, deg } \\ \phi & \text { roll angle, deg } \\ \text { abbreviations } & \\ \text { AGL } & \text { height above ground, ft } \\ \text { CDI } & \text { course deviation indicator } \\ \text { FCS } & \text { flight control system } \\ \text { GPS } & \text { global positioning system } \\ \text { HQ } & \text { handling qualities } \\ \text { HQR } & \text { handling qualities rating } \\ \text { HUD } & \text { heads-up display } \\ \text { ILS } & \text { instrument landing system } \\ \text { KCAS } & \text { calibrated airspeed, kt } \\ \text { mR } & \text { milliradian } \\ \text { NM } & \text { nautical mile } \\ \text { PIO } & \text { pilot-induced oscillation } \\ \text { TACAN } & \text { tactical air navigation set }\end{array}$

\section{INTRODUCTION}

Flight simulation is increasingly being relied upon in the design of new aircraft or modifications to existing airplanes due to the high cost of flight test. The requirements for effective simulation capabilities and the uses of simulation have increased rapidly due to the reduction of funds available for prototyping and the increased complexity of modern airplane flight systems ${ }^{1}$. Historically, piloted simulations have been used very effectively in systems studies, identifying control system problems in gain scheduling, rate limiting, or other control law implementation errors ${ }^{2}$. Actual prediction of flight handling qualities (HQ) using ground-based simulation studies, however, has been less successful. Issues contributing to frequent poor correlation between ground-based and flight handling qualities include psychological, physical, and physiological factors ${ }^{3}$. Many rules of thumb have been arrived at, usually discounting simulation HQ results because experience has shown that the airplane has usually been easier to fly than the simulator. Another

This paper is declared a work of the U.S. Government and is not subject to copyright protection in the United States. 
area in which simulation has not been reliable is the prediction of pilot-induced oscillation (PIO)

characteristics in flight.

In order to rely on simulation in the design and evaluation of new airplane configurations, the strengths and limitations of the tools need to be understood. Many challenges are present when using ground based simulation to evaluate flight handling qualities. Pilots generally are more attentive to workload than task performance when using HQ evaluation scales ${ }^{4}$. This implies that the perception of the $\mathrm{HQ}$ is strongly related to visual or motion cues which help or hinder the pilot in performing the task - regardless of the actual airplane response characteristics ${ }^{5}$. In fact, most measures used to predict longitudinal HQ and PIO characteristics involve pitch rate, pitch rate acceleration, or load factor response ${ }^{6,7}$ which may be very difficult to present to a pilot in ground-based simulation. The present study provides direct correlation of fixed-base ground simulation with flight results using the same 2 pilots, and the same maneuvers in both flight and simulation evaluations. The flight and simulation tests were conducted concurrently to obtain the best possible correlation between simulation and flight. The data obtained included pilot comments and ratings as well as time history information of control inputs, aircraft states and other parameters obtained from the instrumented aircraft.

\section{DESCRIPTION OF AIRCRAFT}

The airplane utilized in this investigation was a General Dynamics F-16XL-1 (Figure 1). This airplane is a derivative of the F-16 made by extending the fuselage, removing the horizontal tails, and incorporating a highly swept cranked delta wing and is one of two F16XL's built. F-16XL-1 is a single-place airplane, and F-16XL-2 was built as a two-place airplane. The test airplane was highly instrumented for aerodynamic and stability and control flight tests, and included air data, global positioning system (GPS) data, Euler angles, angular rates, linear accelerations, control surface positions, and control input force measurements recorded in flight and telemetered to the ground station. Control effectors are elevons and ailerons at the wing trailing edge, and a rudder. Leading edge flaps are also used which are scheduled with angle of attack and Mach number. The flight control system is very similar to the F-16A, with a limited displacement force stick controller. The flight control system imposes an angle of attack limit of approximately $30^{\circ}$ in normal mode, or $20^{\circ}$ in a special reduced angle-of-attack mode which was originally implemented for specific flight test envelope expansion reasons.

The longitudinal flight control laws provide a gcommand system with the landing gear up and at $\alpha$ 's below approximately $19^{\circ}$ in the normal mode, and below $\alpha=10^{\circ}$ in the reduced $\alpha$ mode. For $\alpha$ 's $>19^{\circ}$, (or $10^{\circ}$ in reduced $\alpha$ mode), the pitch command is a blend of normal acceleration and angle of attack. With the landing gear down, the flight control laws transition to a pitch rate command system which blends angle of attack in above $\alpha=10^{\circ}$. The lateral flight control laws provide a roll rate command system. The roll rate command limit is reduced at airspeeds below 250 $\mathrm{KCAS}, \alpha<15^{\circ}$, normal acceleration $>6 \mathrm{~g}$ 's, or with the landing gear extended. The flight control system of the airplane is summarized in reference 8.

\section{DESCRIPTION OF SIMULATOR}

The simulation studies were conducted in the NASALangley Differential Maneuvering Simulator, which is a fixed base 40 -foot diameter dome cockpit simulator". Inflatable seat cushions were employed for $\mathrm{g}$-cueing, however no other motion cueing devices were used. The cockpit was fitted with an actual F-16 sidestick controller. The primary flight instruments were the heads-up display (HUD) which was configured to represent the F-16XL display, and an angle of attack tape, similar to that in the airplane. The simulation math model was originally developed by General Dynamics from wind tunnel data and was subsequently updated from flight test results. Before these simulation tests were flown, a validation study of the simulator was undertaken and time history responses of the simulation were judged to be very representative of the airplane. The simulation math model was a full envelope representation of the airplane including angle of attack, sideslip, Mach and altitude effects on the aerodynamic characteristics.

The simulation used a computer generated visual imagery system for nearly $360^{\circ}$ field of view. The target aircraft used for the tracking and gross acquisition evaluation tasks was displayed on the dome by a separate projector system.

\section{TEST TECHNIQUES}

Evaluation test maneuvers were selected using the simulator. Tasks were selected which involved high gain piloting tasks in order to evaluate the flight characteristics in the longitudinal and lateral axis over a wide range of flight conditions. Additionally, PIO characteristics were evaluated by specifying close 
tolerances required for the tracking and capture tasks selected. Pilot comments were obtained in flight and at the post flight debrief following a question guidelines card which was developed during initial simulator evaluations. In addition to general comments on items such as adequacy of rates, initial response characteristics, predictability of response, undesirable motions/coupling, etc., the pilots gave handling quality ratings (HQR) based on the Cooper-Harper scale ${ }^{11}$ in accordance with the criteria established for each of the maneuvers. Additionally, each of the maneuvers was assessed with a PIO scale rating from the scale shown in table 1 .

Several maneuvers were selected from the STEMS maneuver set ${ }^{11}$ and modified to be applicable in the lower angle of attack range at which these tests were conducted (below $30^{\circ}$ ). All of the target tasks and initial setups were developed in the simulator and then were used in both the simulation and flight evaluations. The primary flight instrument used in the evaluations was the HUD. For tracking and gross acquisition tasks, the HUD displayed a reticle which was depressed $3^{\circ}$ below the aircraft reference line. The reticle had inner and outer rings of $50 \mathrm{mR}$ and $100 \mathrm{mR}$ diameters, respectively. The target aircraft which was available for the flight evaluations was a Northrop T-38A. The target T-38A was equipped with a GPS receiver to allow post-flight analysis of the relative positions of the two airplanes. Because of antenna placement on both the F16XL and T-38A, GPS data was unavailable for most of the maneuvering flight conditions which involved substantial bank angles. Air-to-air TACAN and visual references were used to setup initial conditions for the evaluation tasks in flight. Because of the dissimilar performance capabilities of the two aircraft, some of the tracking tasks involved special setups which were developed in the simulator and subsequently worked well in flight. A list of the maneuvers evaluated and their associated rating criteria is shown in table 2 . Selected data from these tests will be shown.

Two NASA research pilots conducted the flight and simulator evaluations. Flight and simulation tests were conducted concurrently to provide the most valid comparisons possible between simulation and flight.

\section{RESULTS AND DISCUSSION}

Correlation of handling qualities ratings, pilot comments and analysis of flight and simulated time histories of selected maneuvers will be presented in the paper for the following tasks: gross acquisition, steady tracking, roll angle captures, and the ILS landing approach. Where significant differences existed between pilots, data will be shown for both pilots; otherwise, representative data from one pilot will be presented. All of the maneuvers (except the ILS) were initiated at an altitude of $15,000 \mathrm{ft}$. Table 3 lists a summary of pilot ratings for each maneuver discussed.

\section{GROSS ACQUISITION}

Two types of gross acquisition tasks were evaluated. A purely longitudinal acquisition and a multi-axis acquisition. These maneuvers were set up at various speeds and separation distances to evaluate the airplane characteristics across a range of g-loading, pitch rate, and acquisition geometry dynamics. Specific longitudinal gross acquisition examples will be discussed using maneuvers 2.1 and 2.4 from table 2 . The maneuver required 3 acquisitions of the target, each followed by reducing $\theta$ to the horizon. Maneuver 2.1 was initiated at approximately $150 \mathrm{KCAS}$ and $\alpha=15^{\circ}$. The target was co-speed and ahead and above by 6000 and $5000 \mathrm{ft}$., respectively. The maneuver resulted in a large amount of time on the angle-of-attack limiter of $30^{\circ}$ during the capture. Maneuver 2.4 was initiated at an airspeed of approximately $240 \mathrm{KCAS}$ and $\alpha=7.5^{\circ}$. The target was ahead and above by 6000 and $2000 \mathrm{ft}$., respectively. The maneuver maximum angle-of-attack was approximately $20^{\circ}$.

Pilot $\mathrm{HQR}$ ratings for maneuver 2.1 show a discrepancy between the two pilots. Pilot $A$ evaluated the simulation better than flight, whereas pilot $B$ evaluated the simulator worse. Pilot A comments were that in flight there was large amplitude PIO, particularly on the second pull to the target. In the simulator, comments were that after some learning, he could arrive on target with only one overshoot, but that the target had a tendency to "bounce" out of the reticle. Figure 2 shows a comparison of the maneuver between simulation and flight. Flight data is shown for 2 captures, and simulation data is shown for 1 capture. Figure 2 shows the angle-off the nose during the gross acquisition for pilot A. The data show an initial overshoot of the target airplane during the captures in both simulation and flight, however the flight results show more oscillations while trying to keep the target in the reticle. The second capture (flight) shows a divergent PIO with overshoots and undershoots getting progressively larger. The control input time histories, (figure 2), give some insight into the differences between the simulation and flight maneuvers. As pilot comments indicated, in the simulator, the pilot was able to "learn" the task after several practice attempts and developed a procedure to accomplish it. This involved a large (full-scale) initial input then a release of the stick at an appropriate lead angle. After some time to see 
where the airplane settled out, the pilot again began making corrective inputs to keep the target in the desired location. In flight, the pilot did not have the opportunity to repeatably fly the exact same task over and over to develop a "canned" technique. As a result, the pilot was constantly in the control loop with control forces in both directions resulting in oscillations relative to the target. In the second capture, the pilot entered a divergent PIO using full aft control forces.

Pilot $B$ rated the simulator worse than flight, and also rated the flight HQ much better than pilot $\mathrm{A}$. It should be noted that pilot $B$ conducted only one capture for this maneuver in flight, compared to the two conducted by pilot A. Figure 3 shows the comparison of flight and simulator performance of pilot B for maneuver 2.1 . The angle-off nose data shows that both simulation and flight exhibited oscillations in the capture dynamics resulting in slight excursions out of the desired capture criteria. Pilot comments were very similar for both flight and simulation tasks. During evaluations in the simulator and in flight, pilot B commented that the pitch rate was slow and that the configuration had PIO tendencies.

One tendency seen in common to both pilots between simulation and flight was that in the simulation, both pilots had a tendency to use larger pitch inputs early in the maneuvers. This resulted in significantly larger maximum pitch rates in the simulation as shown in figure 4. Pilot $\mathrm{A}$ used $80 \%$ higher maximum pitch rate for the first capture in the simulator compared to flight, while pilot $B$ used $225 \%$ higher maximum pitch rate. The much larger pitch rates used in the simulation by pilot B certainly could be a factor for the decreased HQ ratings in the simulation relative to flight. Absence of tactile cues are probably a primary cause for the difference in pilot technique between simulation and flight for this maneuver. At these low speeds, the pitch rate is low, providing poor visual feedback in the simulator, which combined with the lack of $g$ or pitch rate acceleration cues result in poor correlation between simulation and flight.

At higher speeds, the agreement both between pilots and between simulation and flight improved. Figure 5 shows a comparison of maneuver 2.4 in the simulator and in flight for pilot $\mathrm{A}$. Both simulation and flight show very oscillatory behavior during the capture. Control forces for both simulation and flight have a similar frequency and are indicative of a high pilot workload. Pilot comments for flight were that there was usually one overshoot (time history data show more) and that it was PIO prone. In the simulator, the comments were that the response was oscillatory and that it was similar to the airplane. A constant amplitude PIO developed when attempting to do aggressive captures. If the maneuver was performed less aggressively, then the target could be captured with one or two overshoots. Successful captures required substantial lead in taking out the control input.

Figure 6 shows a comparison of pitch rates used during maneuver 2.4 in the simulator and in flight for both pilots. Again, both pilots used considerably more initial pitch rate in the simulation than in flight. For this maneuver, both pilots had excess control command available, and the captures were occurring at considerably lower $\alpha$ 's (about $15^{\circ}$ vs. $25^{\circ}$ ) than for maneuver 2.1. The improved agreement both between pilots and between flight and simulation for maneuver 2.4 compared to maneuver 2.1 could be related to the increased sensible cues presented to the pilot. At the higher airspeed of maneuver 2.4 , pitch rate, acceleration, and load factor all increased. This allowed more tactile feedback in flight. In the simulator, the increased pitch rate allowed better control through increased visual feedback due to the higher pitch rates, which resulted in better relationships between flight and simulator pilot inputs. Additionally, neither pilot saturated the stick command in flight or in the simulator.

Multi-axis gross acquisitions were conducted to include effects of lateral maneuvering. The maneuver placed the target abeam and flying away from the F-16XI at a $90^{\circ}$ heading difference at $160 \mathrm{KCAS}$. In general, lateraldirectional HQR's for both flight and simulation were very similar. Longitudinal ratings were not as consistent between flight and simulation as seen in the previous maneuver task. Relatively large variability between the pilots for a given maneuver was also seen. Figure 7 compares lateral stick force and roll angle time histories between simulation and flight for maneuver 6.2 for pilot A. As can be seen, very similar roll angles and rates, and control activity were achieved for both flight and simulation. A similar comparison was made with the longitudinal stick force and load factor in figure 8. As can be seen, the simulator was flown with considerably more stick input magnitude resulting in higher load factors. Focusing on the first capture (at time $=18-28 \mathrm{sec}$ ), the lateral control inputs and associated roll rates were similar between simulation and flight. The longitudinal characteristics of the data were very different during the capture as shown in figure 9. The simulator task resulted in large amplitude oscillatory control inputs and load factor response. Flight results show smaller amplitude control inputs and associated load factor responses. These differences may be attributable to the g-cues in flight allowing for smoother aircraft control. Pilot comments for the 
simulation indicated that it was difficult to separate longitudinal and lateral problems, but that there were several overshoots, and very bad PIO (although no PIO rating was assigned). Flight comments were very similar, however the pilot noted that overshoots were primarily side-to-side overshoots in the pull-up and roll maneuver and chose to blame the lateral axis primarily for the overshoots.

Pilot B flew the lateral portion of maneuver 6.2 very similarly between simulation and flight, as did pilot $A$. Additionally, pilot B flew the longitudinal part of the task very similarly between the simulation and flight as shown in figure 10 . This resulted in very similar HQR ratings between simulation and flight. Pilot comments indicated that pilot $B$ downgraded the flight longitudinal HQ rating from 4 to 5 based on his perception of undesired slow pitch rate resulting in excessive time to capture the target.

\section{TRACKING}

Fine tracking tasks were conducted to evaluate the characteristics of the airplane at various speeds, angle of attack and g-loading conditions. Rating criteria were selected to excite PIO tendencies if any existed. Tracking tasks included tracking steady targets and reversing targets. Each of the maneuvers were flown with a separation distance of approximately $1000 \mathrm{ft}$.

During the steady tracking evaluations, both pilots consistently rated the lateral handling qualities of both flight and simulation as meeting desired criteria (HQR ratings 3 or 4 ). Both pilots also rated the airplane as having longitudinal PIO tendencies, with PIO scale ratings of 2 or 3 across the speed and $g$ range tested. In the simulator, pilot $\mathrm{A}$ also rated PIO characteristics the same as flight, however pilot B rated all conditions at $350 \mathrm{KCAS}$ or above as having no PIO tendencies (PIO scale $=1$ ). A detailed look at the pilot comments and data however, reveal that oscillations were occurring in all conditions, but at the higher speeds, pilot B did not identify the oscillations as PIO.

Typical data for steady tracking at $200 \mathrm{KCAS}$ (maneuver 3.4) is shown in figures 11 and 12. Data for pilot $A$ shows continuous oscillations in load factor and stick force in figure 11 . The data show nearly identical magnitudes and frequency of both load factor and stick input for both simulation and flight. Figure 12 shows the results for pilot $B$ for the same maneuver. This data reveal much higher frequency and amplitude results of longitudinal stick inputs and load factor response during flight compared to simulation. The flight characteristics obtained by pilot B look very similar to the simulation and flight results from pilot $A$, however due to learning, reduced stimulus or some other factor, pilot $B$ approached the task differently in the simulator.

Tracking a target during reversals was also evaluated. In the simulator, the target reversed course after a heading change of $30^{\circ}$ for KCAS $\leq 180$, and after $60^{\circ}$ at higher speeds. In flight, the evaluation pilot called for reversals. General results were that both simulation and flight produced PIO tendencies at the higher speeds. As speed decreased, longitudinal handling qualities improved for tracking. This is evident in the PIO scale ratings as shown in figure 13. Results obtained in this test show that the simulator tended to slightly overpredict PIO tendencies, especially at low speeds. Another trend from this data is that PIO tendencies usually resulted in worse HQR's at high speeds in the simulator than in flight. Pilot comments for maneuver 5.1 (150 KCAS) in the simulator were that moderate inputs tended to excite pitch PIO, but the PIO could be suppressed with increased pilot workload. Though workload was elevated to avoid oscillations, desired performance could be achieved. In flight, comments indicated occasional PIO or "bobbles" following corrective inputs, but otherwise solid desired performance. At higher speeds, maneuver 5.5, simulator HQR's were significantly worse than flight ratings, however the pilot comments were very similar. Both pilots' comments in the simulator included continuous PIO, sawing through the CG of the target, and target bouncing out of reticle. In flight comments were that there was continual moderate PIO.

Comparison of data between simulator and flight for maneuver 5.5 (figure 14) show increased amplitude of longitudinal inputs in the simulator, but the inputs were at a similar frequency as observed in flight. Although angle-off data is not available from flight due to GPS limitations previously discussed, simulator results in figure 15 show continuous oscillations during the tracking, but even while reversing course, the target remained within the $50 \mathrm{mR}$ reticle.

\section{ROLL ANGLE CAPTURES}

\section{$\phi$ CAPTURES 1-g:}

Aircraft bank angle $(\phi)$ captures were conducted to evaluate lateral handling qualities and control of the aircraft at four different angles of attack, which were produced by varying maneuver speed and are listed in table 2. The maneuver was initiated while wings were level and at constant speed and altitude. Bank angles were captured in a sequence of -60 (left bank), 60 (right bank), and 0 degrees. The three sub-phases of the 
maneuver are referred to as maneuver entry, roll back, and roll out. Maneuver 1.4 could not be accomplished at constant airspeed due to large amounts of nose down control being generated by the control system as a response to roll rate and was only attempted by one of the pilots in flight.

Analysis of the resulting data for both simulated and actual flight showed desired performance for all bank angle captures attempted. Additionally, pilot inputs, and aircraft performance were similar for both simulated and actual flight results. Figure 16 shows bank angle, roll rate, roll rate acceleration, and pilots lateral stick input for maneuver 1.2 and is representative of all other l-g $\phi$ captures for both pilots. From this figure the similarities between flight and simulator results are obvious. An evaluation of maximum roll rate and maximum roll rate acceleration for the three sub-phases of the maneuver was performed and results for flight are plotted against results obtained for an identical maneuver sub-phase from simulation in figure 17. Lines representing values which are equal to, $\pm 20 \%$ and $\pm 40 \%$ of simulator results are included in figure 17 as a guide to interpret the comparison. From this figure it can be seen that a majority of points fell below the line where flight results were equal to simulator results for maximum roll rate and roll rate acceleration. Table 4 presents a distribution of maximum roll rate and roll rate acceleration values in flight relative to simulation maximum values.

From this table it can be seen that generally pilots used less roll rate and roll rate acceleration in flight than in simulation. This result can be attributed to the lack of motion cues in the fixed-base simulation which are, of course, present in flight. However, motion cues are usually assumed to affect roll rate acceleration, which the pilot feels, not roll rate which the pilot sees. The above table and associated figure show much more significant reductions for flight results in roll rate than roll rate acceleration, which is an unexpected result.

Pilot remarks and handling quality ratings were similar for both simulator and flight. However, there was some perception by the pilots that adequate performance was not being achieved especially in the simulator. As mentioned above, desired performance was achieved for all bank angle captures both in flight and in the simulator. Pilot remarks indicated that lateral sideforce cues combined with outside visual cues made it much easier to evaluate roll characteristics such as roll rate and damping, and to feel roll rate non-linearities. Pilots also commented that technique was important and that the limited displacement force stick made it difficult to determine maximum control inputs. For the two slower airspeeds (KCAS $=100$ and 130), pilots downgraded the maneuver by increasing the resulting HQR 2 to 3 units as a result of less than acceptable roll rate available. This level of $H Q R$ degradation was common for both simulation and flight. The HQR values presented in table 3 were results obtained without consideration of the roll rate available criteria.

\section{ф CAPTURES elevated-g:}

Elevated-g $\phi$-captures were conducted to evaluate lateral handling qualities and control in conjunction with a longitudinal task of maintaining constant normal gloading. Different combinations of aircraft speed and gloading were employed to evaluate aircraft handling qualities for an angle of attack range from 7 up to 18 degrees, and are listed in table 2. The maneuver was initiated from left-wing-down turning flight at constant speed and slightly varying altitude. Pilots adjusted longitudinal stick force to obtain the specified initial gloading at $\phi=-60$ (left bank) degrees. Bank angles were captured in a sequence of 60 (right bank), and -60 degrees. The two sub-phases of the maneuver are referred to as maneuver roll back, and roll out.

Analysis of the resulting data for both simulated and actual flight showed desired lateral performance for all bank angle captures attempted. Additionally, pilot inputs, and aircraft performance were similar for both simulated and actual flight results. Figure 18 shows data from maneuver 8.3 and is representative of all of the elevated-g $\phi$ captures flown. From figure 18a, the similarities between flight and simulator results are obvious for lateral performance. Similarities also exist for longitudinal performance (figure 18b), however the pilots did not obtain desired accuracy for most of the maneuver, and even experienced some short excursions beyond adequate limits. The relatively poor longitudinal performance was partially due to the inadequacy of the HUD display for this task.

An evaluation of maximum roll rate and maximum roll rate acceleration for the two sub-phases of the maneuver was performed. Figure 19 presents results for flight plotted against results obtained for an identical maneuver sub-phase from simulation. Lines representing values which are equal to, $\pm 20 \%$, and \pm $40 \%$ of simulator results are included in figure 19 as a guide to interpret the comparison. From this figure it can be seen that a majority of points fell below the line where flight results were equal to simulator results for maximum roll rate and roll rate acceleration. Table 5 summarizes the percentage of points in each plot region. 
From table 5 the same trends seen in the 1-g $\phi$-captures are evident - that generally pilots used less roll rate and roll rate acceleration in flight than in simulation. A total of $87 \%$ of the maneuver sub-phases performed in flight employed less roll rate than the identical maneuver sub-phase performed in simulation as compared to $63 \%$ for roll rate acceleration.

Pilot remarks and handling quality ratings were similar for both flight and ground based simulation. As mentioned above, desired lateral performance was achieved for all bank angle captures both in flight and in simulation. Pilots remarked that concentrating on maintaining g-forces, through the use of the HUD $g$ presentation, or a heads-down angle of attack gauge, heavily detracted from the bank angle capture performance. Relying on body forces to gauge normal acceleration also did not yield adequate results for maintaining desired or even adequate performance levels. Roll rate non-linearities caused by angle of sideslip build-up during the maneuver were observed in ground based simulation and flight. Lateral sideforce cues combined with outside visual cues made it much easier to evaluate roll characteristics such as roll rate and damping, and to feel roll rate non-linearities. Pilots also commented that the simulator "felt" like the airplane without the neck-snapping acceleration cues. As a result they were less likely to use sudden stick inputs in flight, which is also confirmed through analysis of the available data. The HQR values presented in table 3 were results obtained based on lateral performance alone.

From table 3 it can be seen that pilot $B$ generally rated flight one HQR unit better than the same maneuver performed in ground-based simulation. Otherwise identical HQR results were obtained for all elevated-g $\phi$ captures.

\section{ILS Sidestep Approach to Landing}

An ILS task was evaluated to determine the correlation value of a maneuver which involved tight tolerances on aircraft flight path control and a large lateral repositioning of the aircraft in close proximity to the ground. There were three sub-phases of the ILS maneuver, which are presented in figure 20 . As can be seen in this figure a simulated localizer/glideslope approach was established with an offset of 840 feet from the runway centerline. Adiagram presenting important elements of the HUD ILS guidance used by the pilots is shown in figure 21 .

The maneuver began in flight with the pilot flying the aircraft to a waypoint using the inertial navigation system of the aircraft which placed the aircraft a distance of two nautical miles, as measured along the intercept course, from the localizer intercept point. When this maneuver was performed using the ground-based simulator, initialization of the maneuver was at the waypoint. Once at the waypoint, the aircraft was flown on a $30^{\circ}$ lateral intercept of the localizer course. At approximately $8 \mathrm{NM}$ from the runway threshold an intercept of the localizer was performed with the aircraft at 2,000 ft. AGL. Intercept of the glideslope occurred at about $6 \mathrm{NM}$ from runway threshold. This was the first sub-phase of the maneuver and is referred to as localizer/glideslope intercept. The second sub-phase required the pilot to track the localizer/glideslope course. The final sub-phase of the maneuver was the sidestep to landing, which was initiated at an altitude of $300 \mathrm{ft}$. AGL. The entire approach was flown without the use of a flight director, which increased pilot workload compared to normal ILS approaches in this airplane.

Analysis of the resulting data showed similar performance of the maneuver from both flight and ground-based simulation. Pilots had little difficulty with the localizer/glideslope intercept sub-phase of the ILS maneuver with regards to aircraft position.

However, less than adequate performance of airspeed management was noticed for all ILS intercepts performed. Pilots tended to focus attention on accurate management of trajectory performance rather than on precise airspeed control. This could be due to the low number of ILS maneuvers performed and minimal speed cues afforded to the pilot by the FCS and sidestick controller. Desired performance (other than airspeed) was achieved during the intercept with only minor excursions, which were well within the desired range, before stabilization on the localizer/glideslope course in flight. In addition, similar bank and pitch angles and stick force activity were apparent between simulation and flight.

Desired trajectory performance was accomplished during the localizer/glideslope tracking portion of the ILS maneuver. Results were very similar between flight and simulation, except the speed used in the simulator tended to be up to $20 \mathrm{kts}$. less than used in flight.

The final sub-phase of the ILS maneuver was the sidestep to landing, which was specified to begin at an altitude of 300 feet AGL. Figure 22 presents aircraft distance from runway centerline, bank angle, and lateral stick force as a function of distance from runway threshold. Figure 23 presents aircraft altitude, angle of attack, pitch attitude, and longitudinal stick force. The specified touchdown point was located approximately 1,049 feet down the runway and on the centerline. As can be seen in figure 22 and 23 , pilot workload increased dramatically as pilot progressed through the sidestep maneuver. Initially pilot activity was mainly 
an increase in lateral commands. However, as the pilots began rolling out of the second part of the sidestep maneuver, pitch activity increased rapidly for flight and was not as pronounced in the ground-based simulation data as can be seen in figure 23. Pilots tended to not be as aggressive to acquire the designated touchdown point in ground-based simulation as can be seen by the more gradual flare in the altitude results. Neither groundbased simulation or flight results produced desired, or even adequate results for touchdown distances. Flight results were much closer to the desired touchdown point than for ground-based simulation with and average of $540 \mathrm{ft}$. short of the specified touchdown point for flight as compared with 2,203 ft. passed the desired touchdown point for ground-based simulation. Although very few ILS task evaluations were conducted, they do reveal trends. Pilots were capable of controlling touchdown rate better in flight, in spite of landing before the specified touchdown point, and averaged approximately $2.5 \mathrm{ft} / \mathrm{sec}$ as compared with $3.4 \mathrm{ft} / \mathrm{sec}$ for simulation.

Pilot ratings for the localizer/glideslope intercept and tracking sub-phases of the maneuver were almost identical in flight and simulation. Comments indicated the maneuver was not difficult to perform and generally attained desired performance both in flight and in ground-based simulation. HQR ratings of 3 were generally assigned by both pilots for the two initial sub-phases of the ILS maneuver for lateral and longitudinal tasks. Pilot A rated the lateral part of localizer/glideslope tracking a 4 due to continual Sturning across the desired course. The sidestep subphase of the ILS maneuver received a HQR of 7 by both pilots for ground-based simulation and from pilot $A$ in flight. Pilot $B$ rated the sidestep maneuver in flight a HQR of 4, but began the maneuver higher than the specified $300 \mathrm{ft}$. AGL. Comments cited the need to go below the previously tracked glideslope flight path to touchdown at the specified point as a significant problem. The touchdown point was specified to be adjacent to where the glideslope intersected the ground. Pilot B commented that the sidestep maneuver should have been started at 400 to $500 \mathrm{AGL}$ instead of 300 feet. This pilot aborted his first flight attempt of the sidestep maneuver, which was initiated at $300 \mathrm{ft}$. AGL, at an altitude of approximately $40 \mathrm{ft}$. AGL. Both pilots commented that lack of clear peripheral visual cues, inherent to the dome simulator visual system, impaired the ability to judge the height above the runway and made precision landing impossible. No comments were made regarding the lack of motion cues for ground-based simulation as a limiting factor.

\section{CONCLUDING REMARKS}

A flight test validation of several handling qualities tasks has been conducted on a high performance airplane with a highly swept wing to compare with results from a fixed-base dome simulator. These results give guidance to which classes of evaluation maneuvers are likely to give comparable results in the simulator, and what differences one may expect when evaluating an airplane using piloted simulation prior to flight, or in the design stage. Specific results are as follows:

1. Task learning in the simulator can result in better handling qualities ratings in simulator than in flight.

2. Pilot input magnitudes, especially in pitch, tend to be much greater in the simulator than in flight particularly at lower airspeeds - probably due to reduced feedback cues. At slow speeds, pitch rate is slow, so visual feedback in the simulator is weak.

3. Lateral inputs are similar across the speed range. The relatively high roll rates provide good visual cues in the simulator and show that for lateral control, visual cues are probably more important than acceleration cues.

4. When the simulation is flown with initial inputs similar to flight, much better agreement between flight and simulation HQR's result. This indicates that pilot approach can have a large impact on simulator-to-flight correlation.

5. Pilot induced oscillations were observed both in the simulator and in flight, and were more pronounced in the simulator at slow speeds during the fine tracking tasks.

6. The ILS sidestep maneuver was valuable for evaluating a high gain task. Good correlation between flight and simulation is evidence that the motion cues are not a primary factor in assessing handling qualities for this task. The touchdown task was not suitable to be used in the simulation for flight correlation.

Future plans include a more thorough review and analysis of the flight and simulation data. A piloted simulation study with motion should be conducted to evaluate the postulated importance of pitch rate acceleration and/or g-cues on low-speed gross acquisition tasks. Finally, although this study included too few pilot samples to give definitive answers, it has shown that simulation-to-flight comparisons can be very good, but are highly dependent on pilot technique and therefore may vary from pilot to pilot. 


\section{REFERENCES}

1. Borowski, R. A.: Piloted Simulation Effectiveness Development Applications and Limitations. AGARD CP-513, February 1992.

2. Keller, K. L., Janzen, D. B., and Asay, A. A.: Utility of Ground Simulation in Flight Control Problem Identification, Solution Development and Verification. AGARD CP-513, February 1992.

3. Reynolds, P. A., and Gawron, V. J.: When InFlight Simulation is Necessary. AIAA-90-3130CP.

4. Lindsey, S. W.: Prediction of Longitudinal Pilot Induced Oscillations Using the Optimal Control Model. AFIT Thesis, December 1989.

5. Mitchell, D. G., Hoh, R. H., Atencio, A. Jr., and Key, D. L.: The Use of Ground Based Simulation for Handling Qualities Research: A New Assessment. AGARD CP-513, February 1992.

6. Gibson, J. C.: Handling Qualities for Unstable Combat Aircraft. ICAS-86-5.3.4, September, 1986.

7. Military specification, Flying Qualities of Piloted Airplanes. MIL-F-8785C, 1980.

8. Ogburn, M. E., Nguyen, L. T., and Brown, P. W.: Simulation Study of a Cranked-Arrow-Wing Fighter Configuration at High Angles of Attack. NASA TM-85800, November, 1984.

9. Ashworth, B. R., and Kahlbaum, W. M., Jr.: Description and Performance of the Langley Differential Maneuvering Simulator. NASA TND7304, 1973.

10. Cooper, G. E., and Harper, R. P., Jr.: The Use of Pilot Rating in the Evaluation of Aircraft Handling Qualities. NASA TN D-5153, 1969.

11. Wilson, Riley, and Citurs: Aircraft Maneuvers for the Evaluation of Flying Qualities and Agility.

WL-TR-93-3082. August, 1993.

\begin{tabular}{|l|c|}
\hline \multicolumn{1}{|c|}{ Description } & $\begin{array}{c}\text { Numerical } \\
\text { Rating }\end{array}$ \\
\hline $\begin{array}{l}\text { No tendency for pilot to induce } \\
\text { undesirable motions. }\end{array}$ & 1 \\
$\begin{array}{l}\text { Undesirable motions tend to occur } \\
\text { when pilot initiates abrupt maneuvers } \\
\text { or attempts tight control. These } \\
\text { motions can be prevented or eliminated } \\
\text { by pilot technique. }\end{array}$ & 2 \\
$\begin{array}{l}\text { Undesirable motions easily induced } \\
\text { when pilot initiates abrupt maneuvers } \\
\text { or attempts tight control. These } \\
\text { motions can be prevented or eliminated } \\
\text { but only at sacrifice to task } \\
\text { performance or through considerable } \\
\text { pilot attention and effort. }\end{array}$ & \\
$\begin{array}{l}\text { Oscillations tend to develop when pilot } \\
\text { initiates abrupt maneuvers or attempts } \\
\text { tight control. Pilot must reduce gain } \\
\text { or abandon task to recover. }\end{array}$ & \\
$\begin{array}{l}\text { Divergent oscillations tend to develop } \\
\text { when pilot initiates abrupt maneuvers } \\
\text { or attempts tight control. Pilot must } \\
\text { open loop by releasing or freezing the } \\
\text { stick. }\end{array}$ & 4 \\
Disturbance or normal pilot control \\
may cause divergent oscillations. \\
Pilot must open control loop by \\
releasing or freezing the stick.
\end{tabular}

\section{Table 1. PIO rating scale}




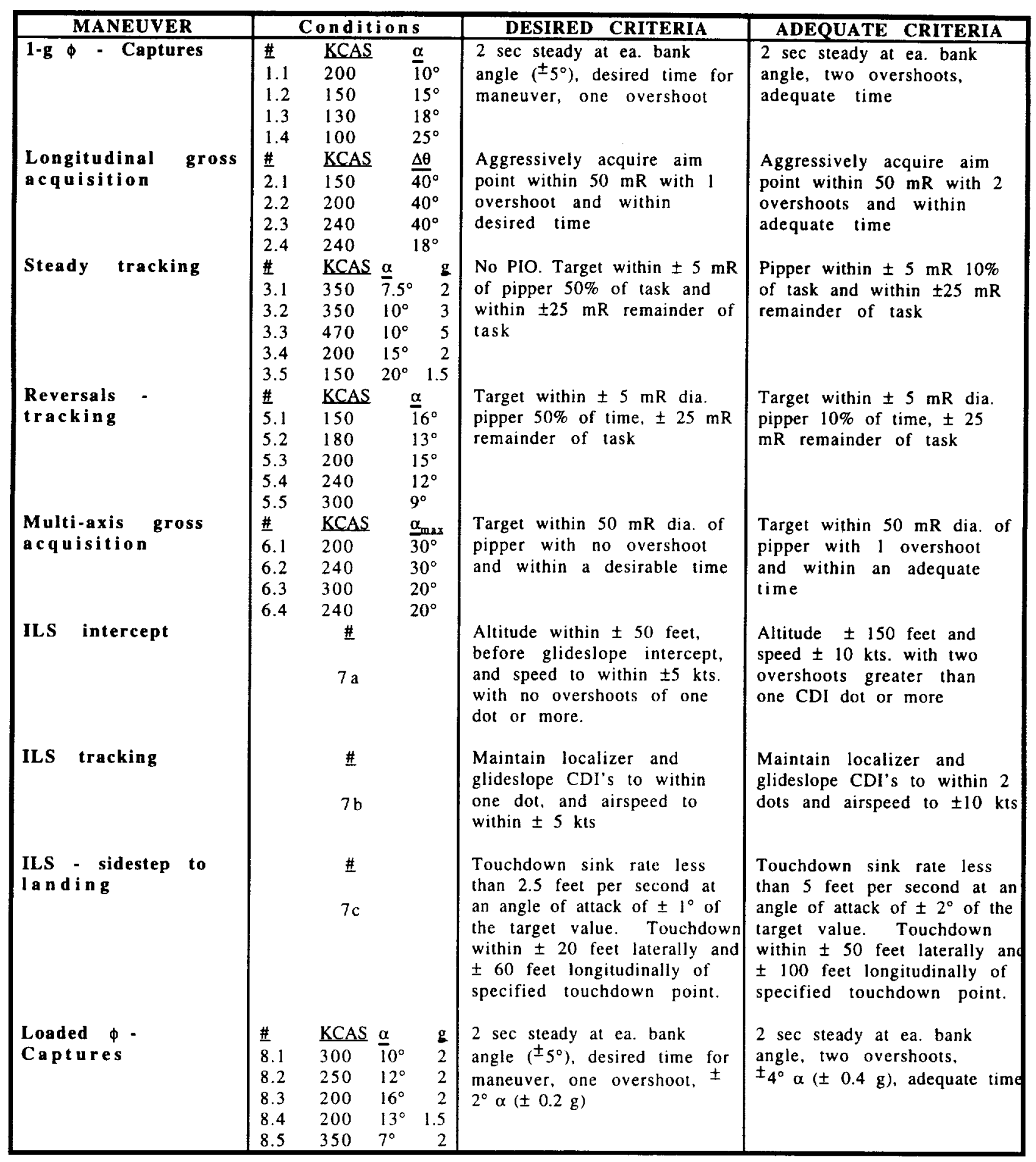

Table 2. Rating criteria 


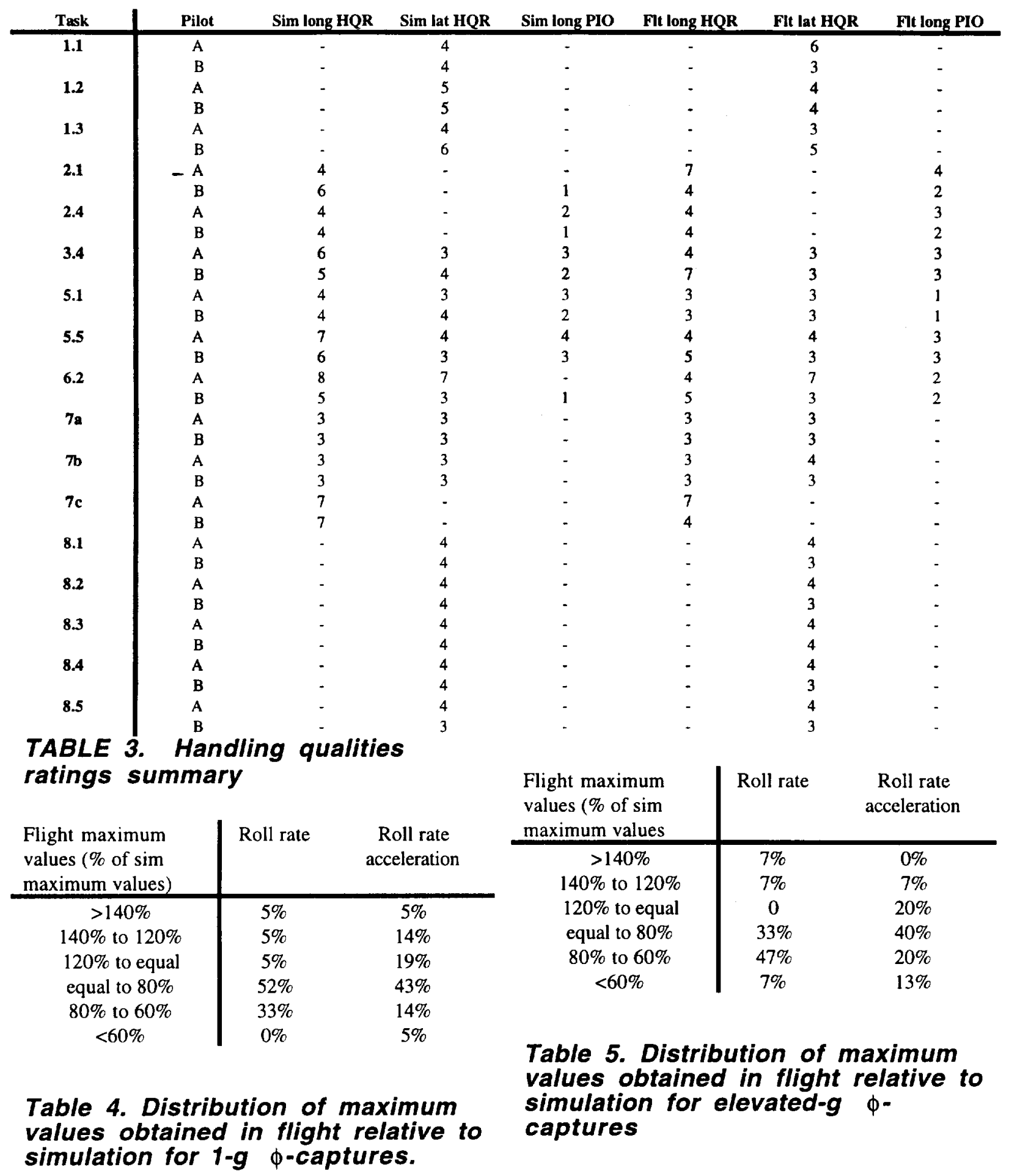




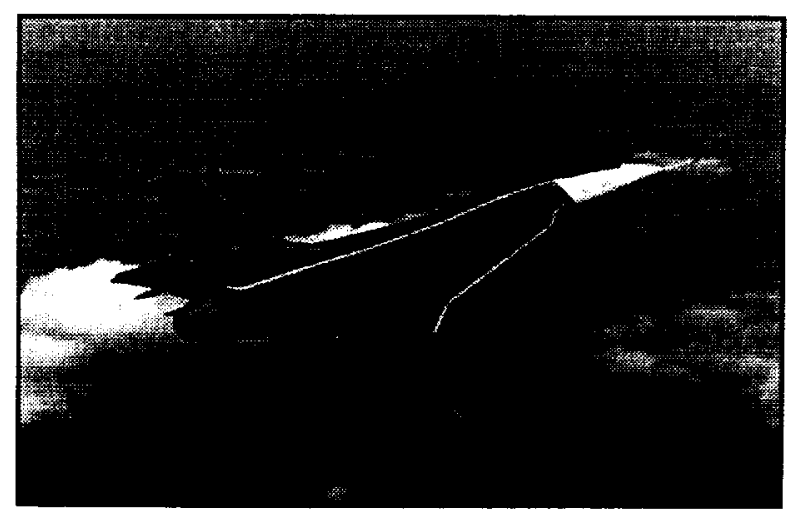

Figure 1.- F-16XL -1 test alrplane
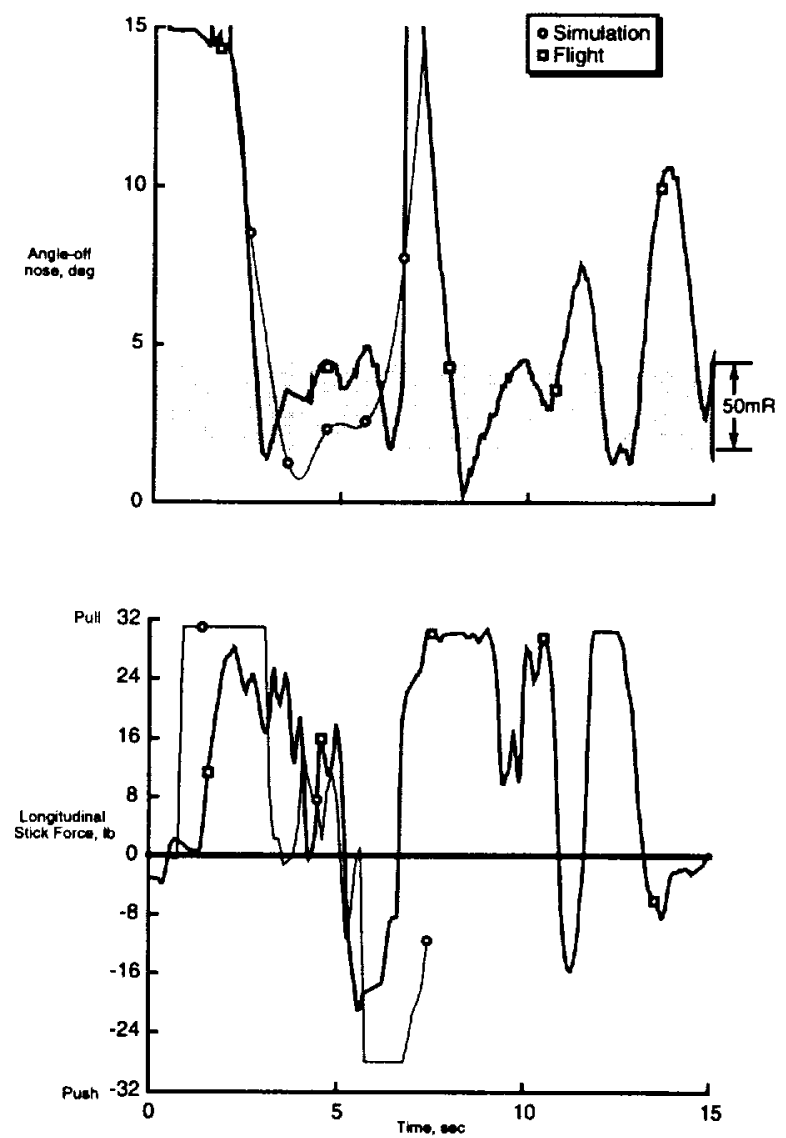

Figure 2.- Longitudinal gross acquisition, maneuver 2.1, pllot A.
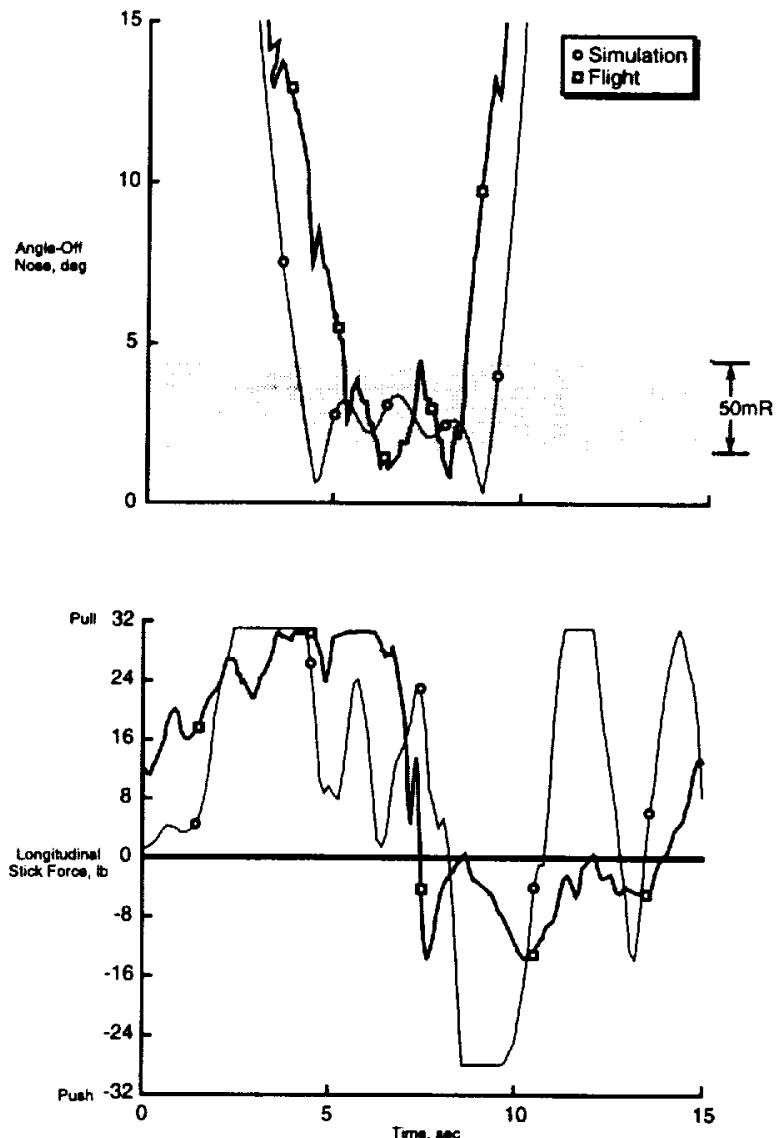

Figure 3.- Longitudinal gross acquisition, maneuver 2.1, pllot B 

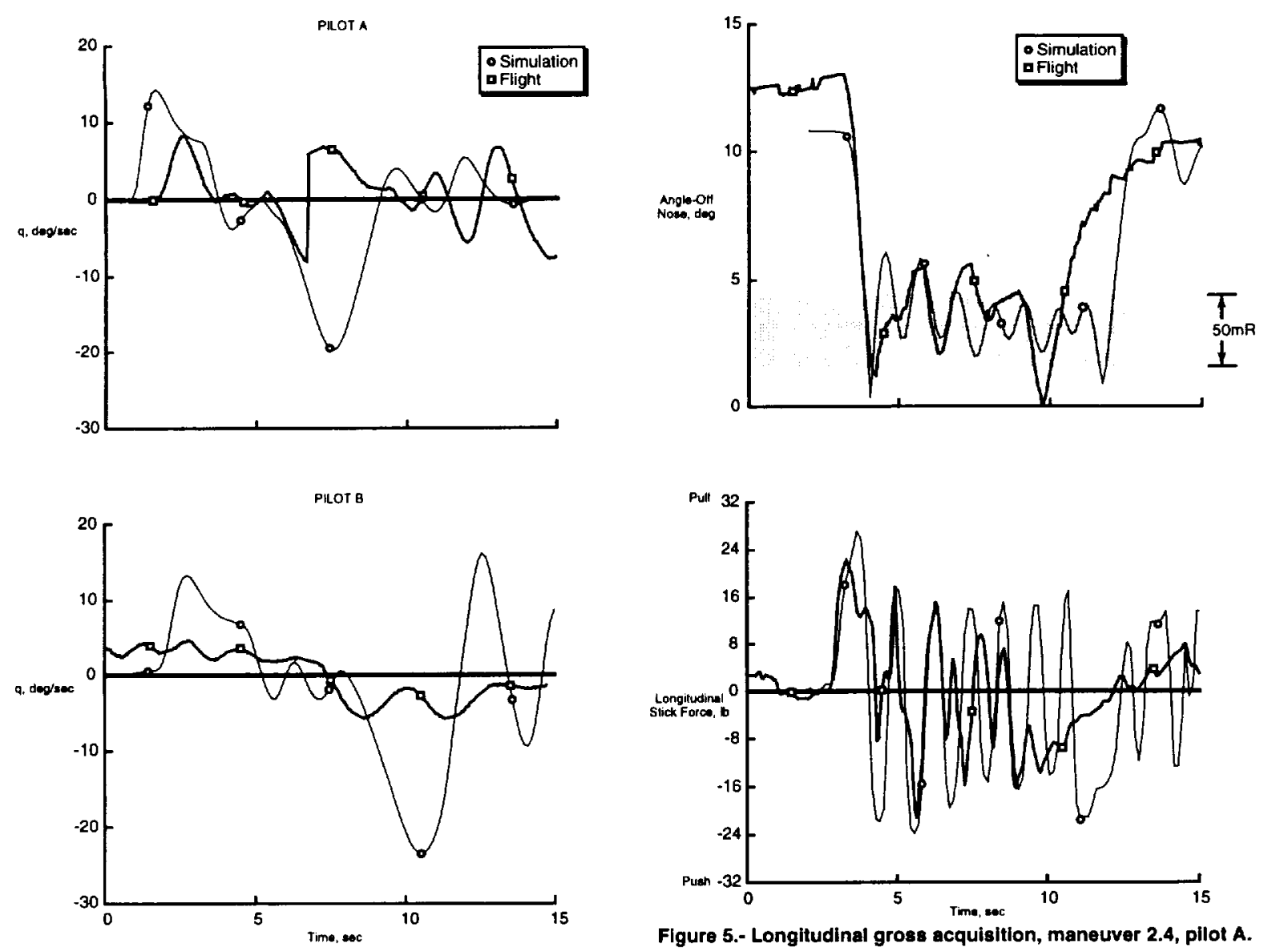

Figure 4.- Pitch rate comparison, maneuver 2.1 

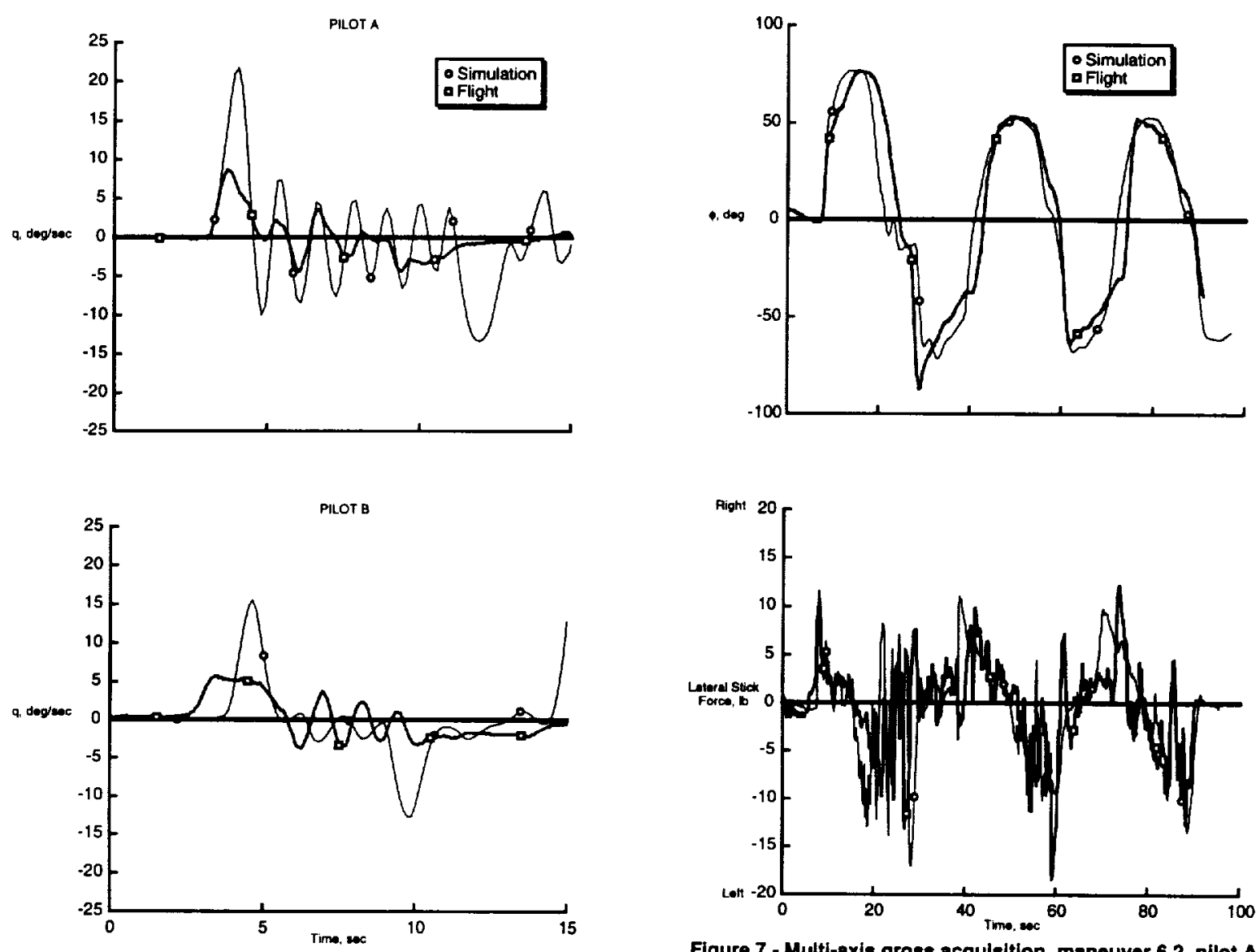

Figure 6.- Pitch rate comparison, maneuver 2.4 .

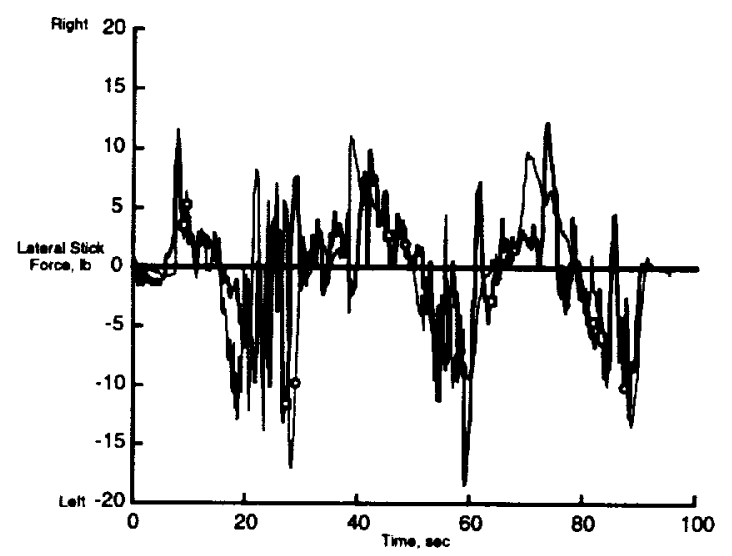

Figure 7.- Multi-axis gross acquisition, maneuver 6.2, pilot A. 

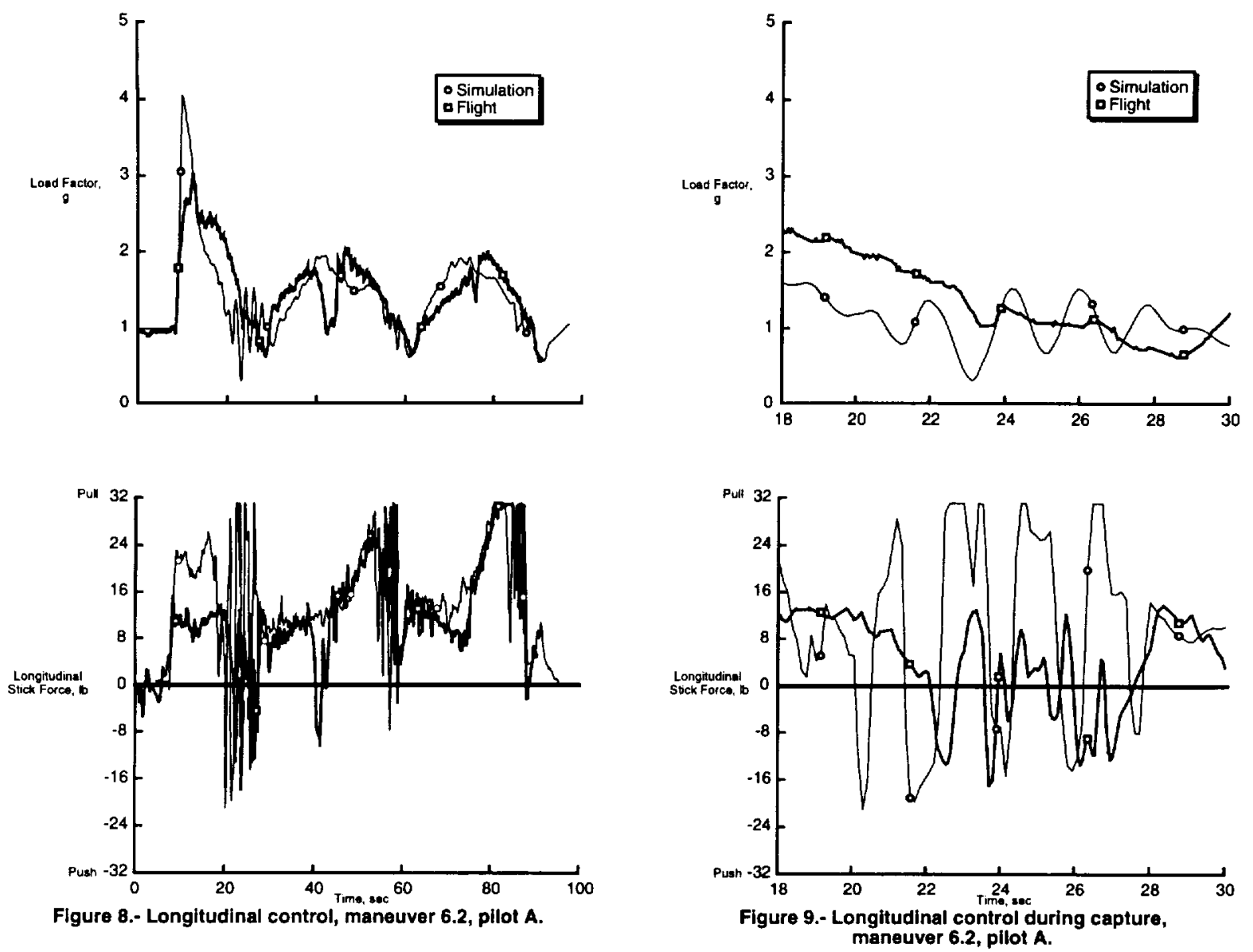

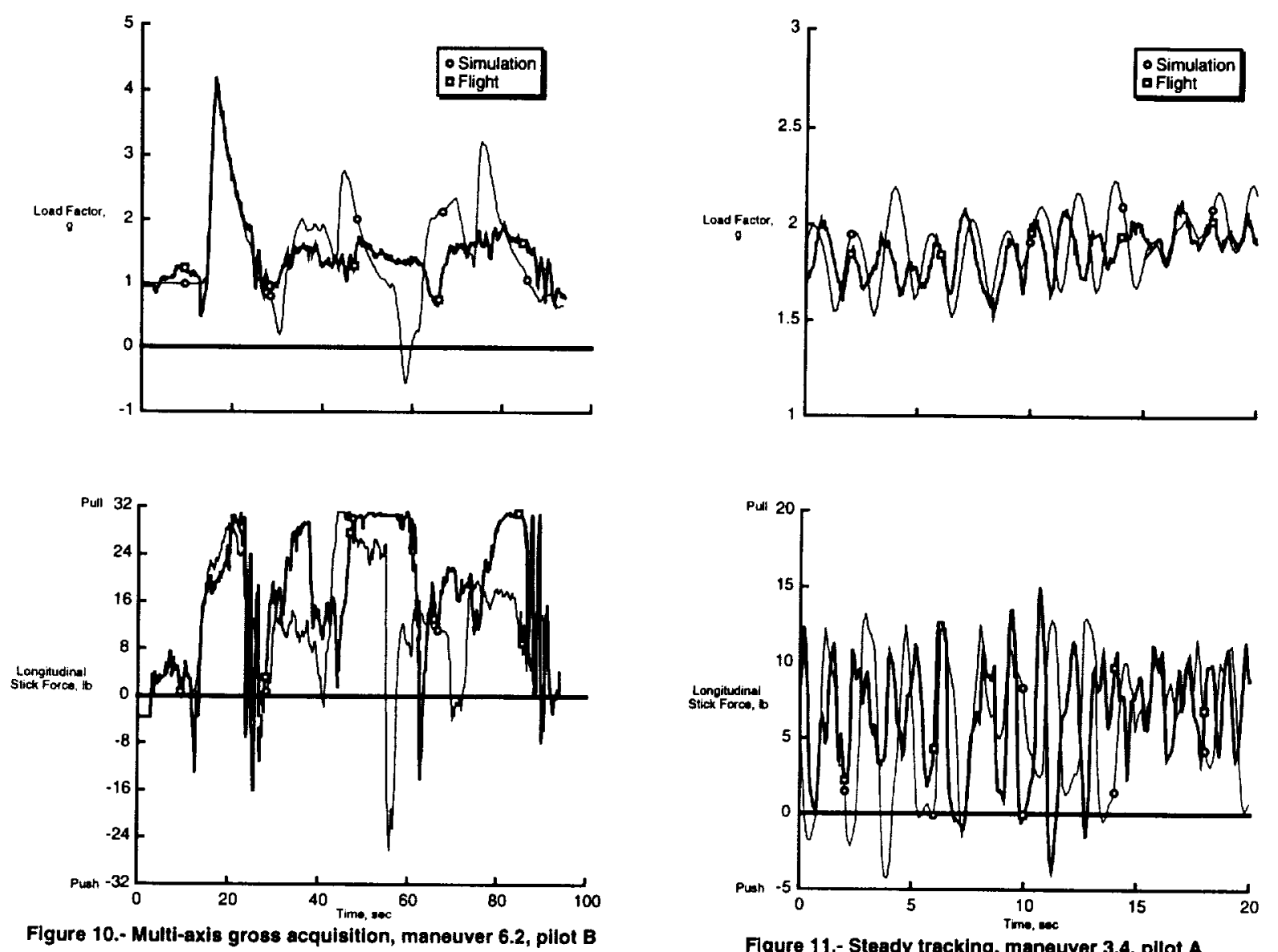

Figure 10.- Multi-axis gross acquisition, maneuver 6.2, pllot B

Figure 11.- Steady tracking, maneuver 3.4, pllot A 

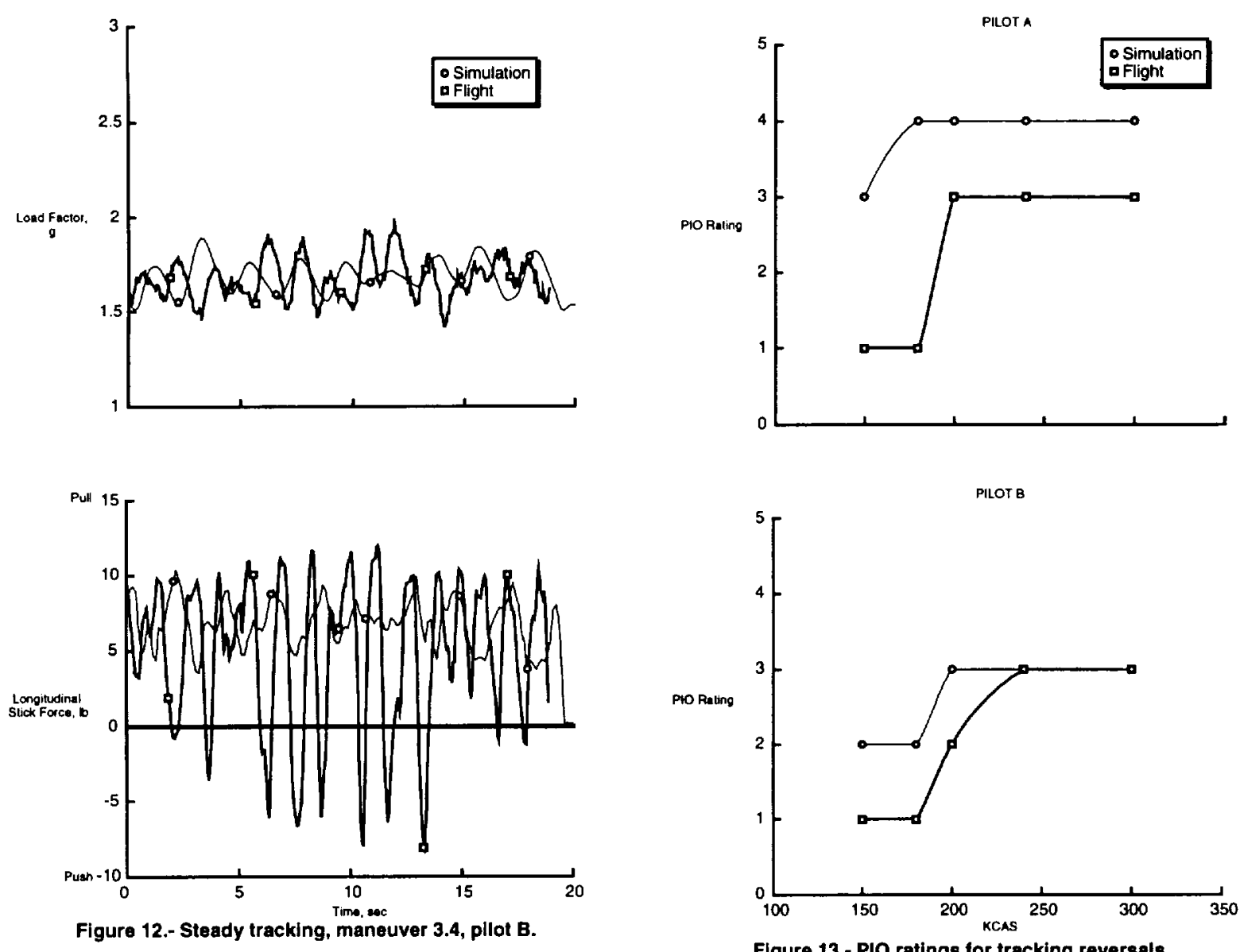

Figure 12.- Steady tracking, maneuver 3.4, pllot B.

Figure 13.- PIO ratings for tracking reversals. 

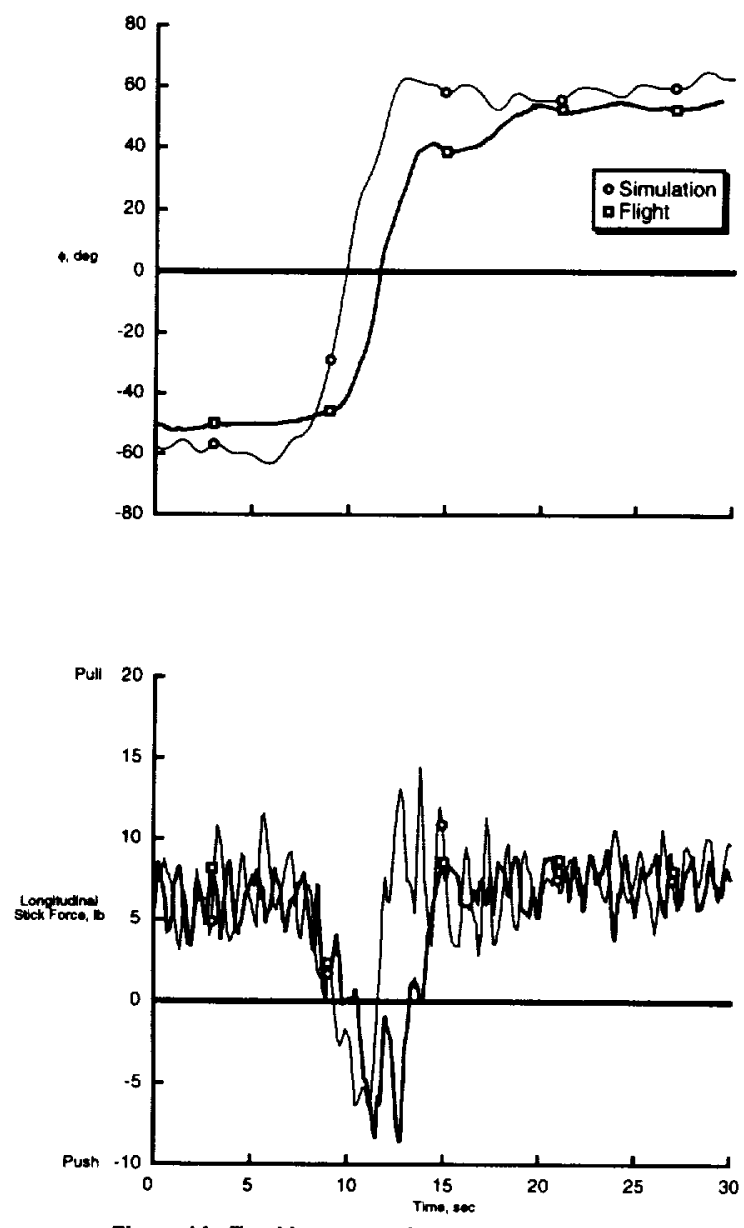

Figure 14.- Tracking reversal, maneuver 5.5, pilot $B$.

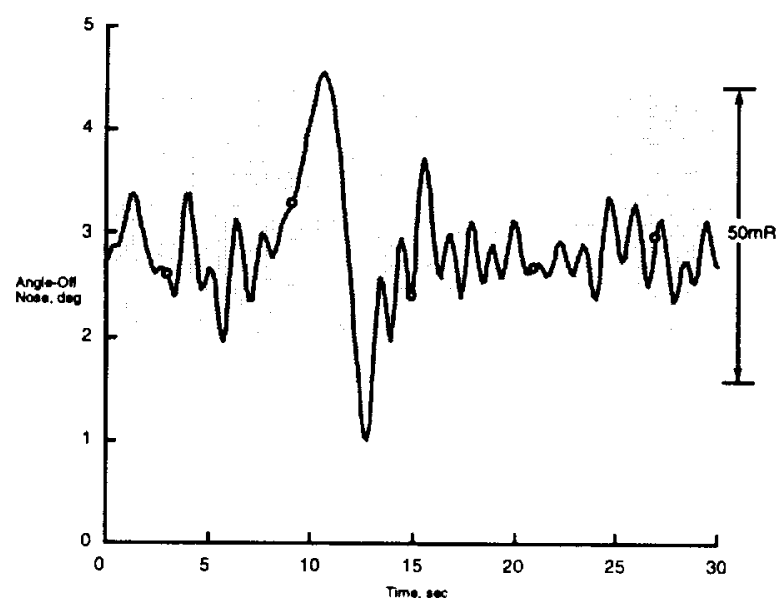

Figure 15.- Tracking results in simulator, maneuver 5.5, pllot $B$.
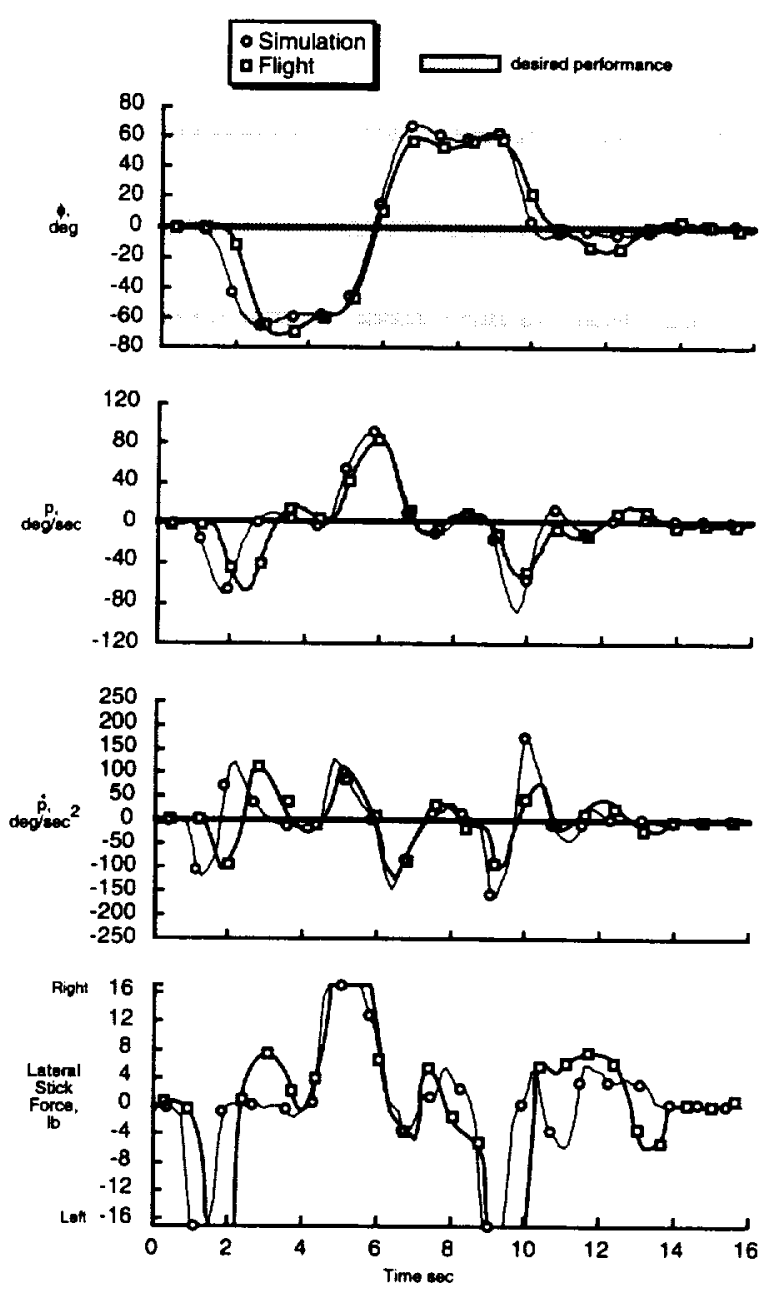

Figure 16.- $1-9$ captures, maneuver 1.2, pllot $B$. 

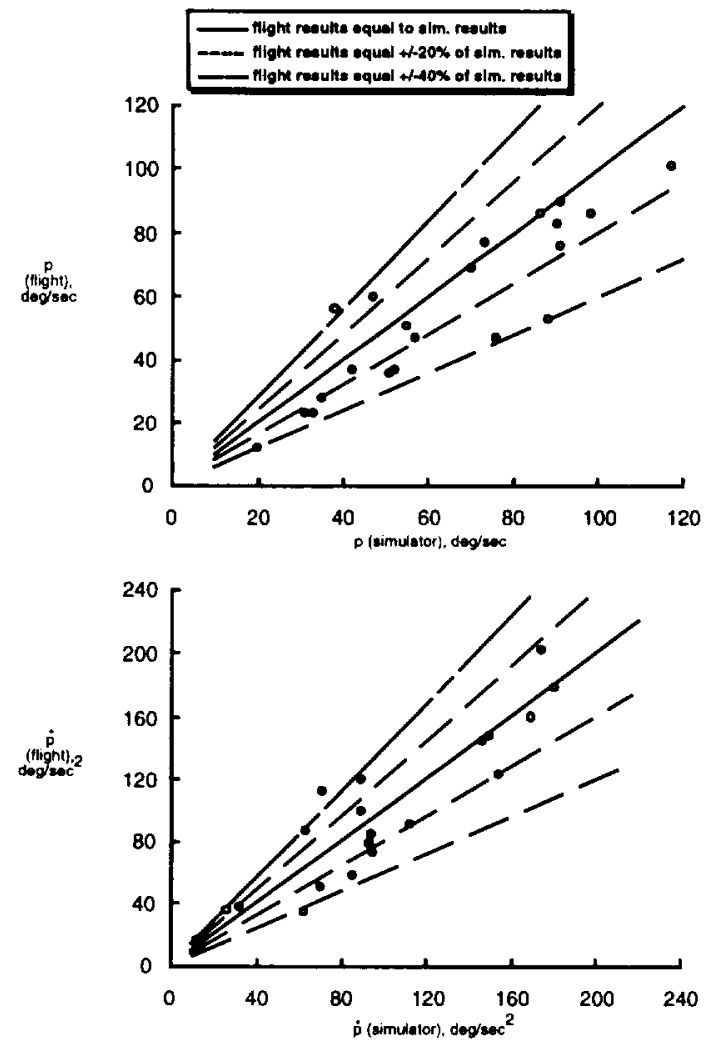

Figure 17.- Summary of maximum roll rate and maximum roll rate acceleration for 1-g $\phi$ capture maneuver during maneuver entry, roll back, and roll out sub-phases.
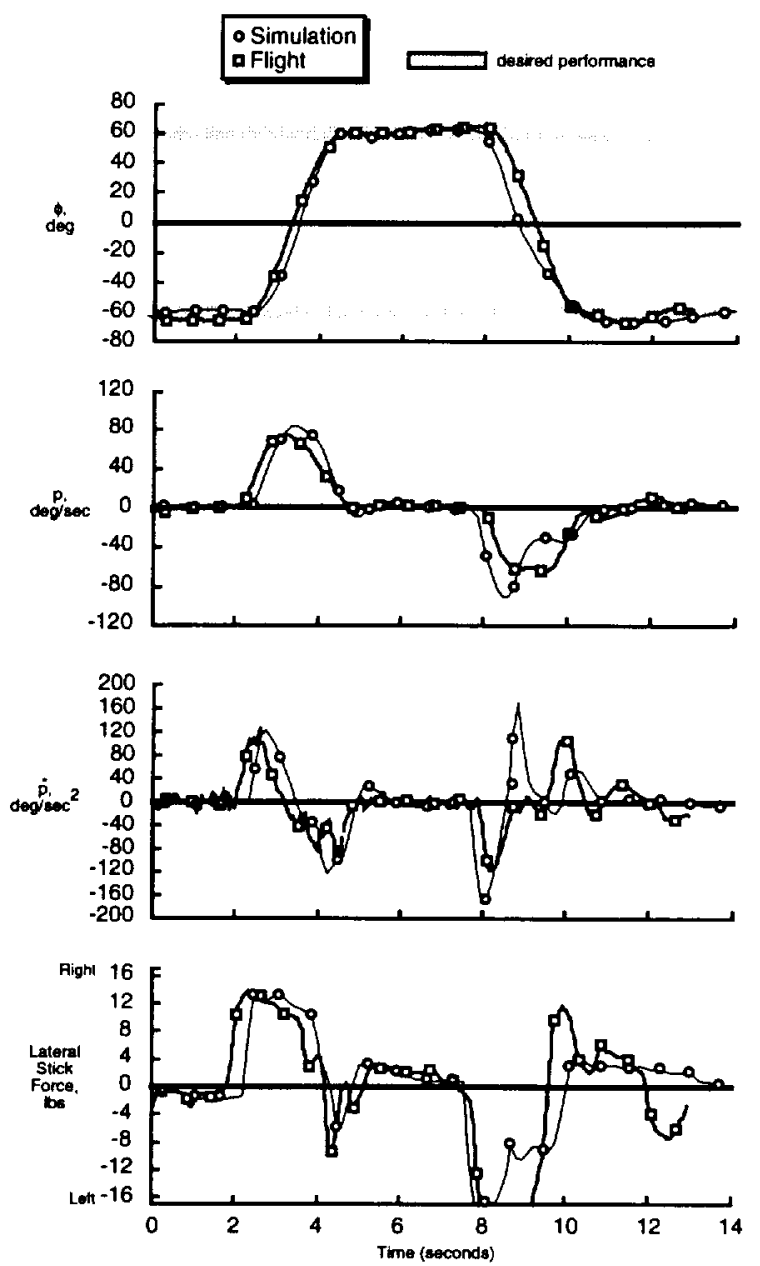

Figure 18a.- Elevated-g $\phi$ captures, maneuver 8.3 , pilot A. 

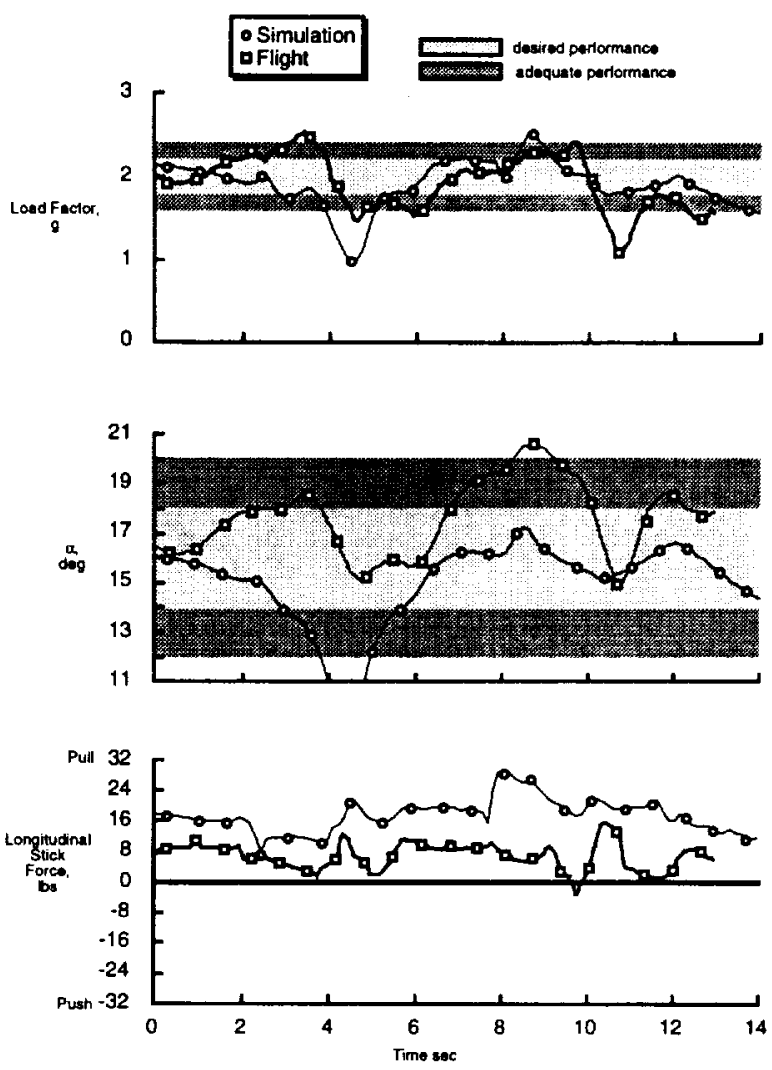

Figure 18b.- Elevated-g $\phi$ captures, maneuver 8.3, pllot A.
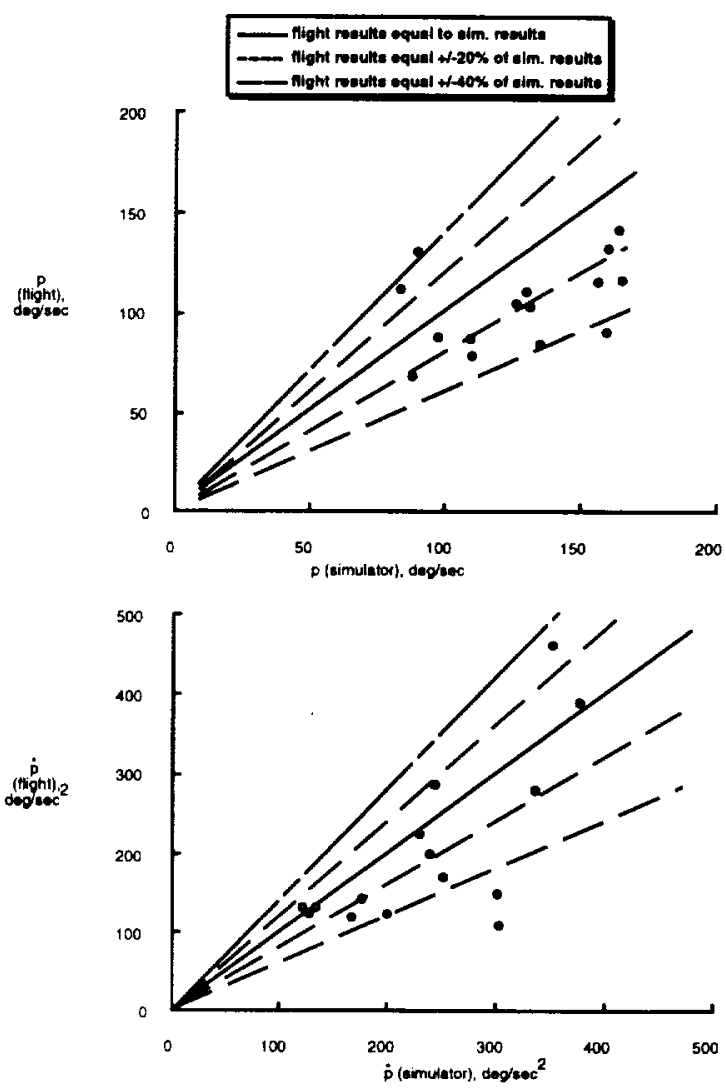

Figure 19.- Summary of maximum roll rate and rolt rate acceleration for elevated-g captures during roll back and roll out sub-phases.

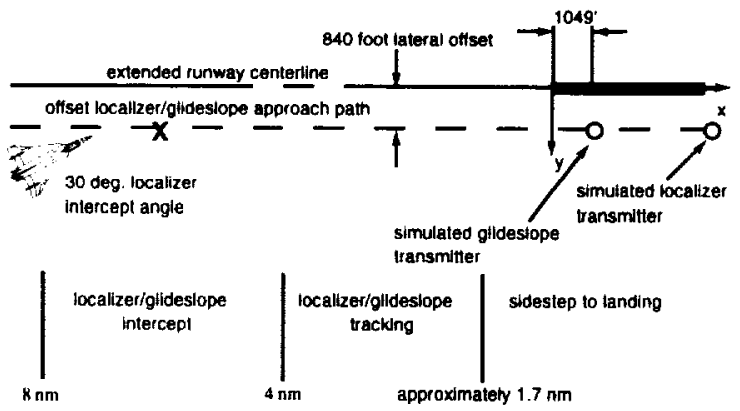

$X=g$ lidestope Intercepl at 2000 teet $A G L$ at $6 \mathrm{~nm}$ from runway threshold

Figure 20.- Definition of ILS-offeet approach and maneuver sub-phases. 

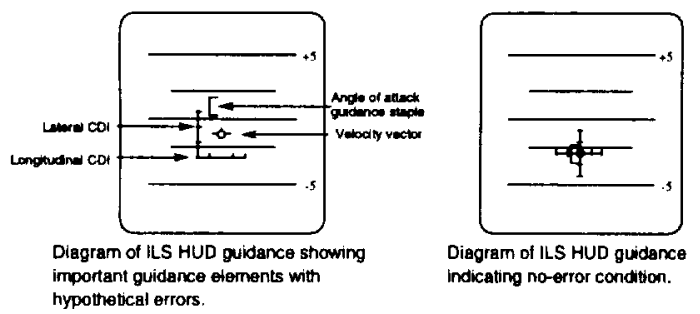

Figure 21.- Dlagram of ILS HUD guidance employed for ILS maneuver.
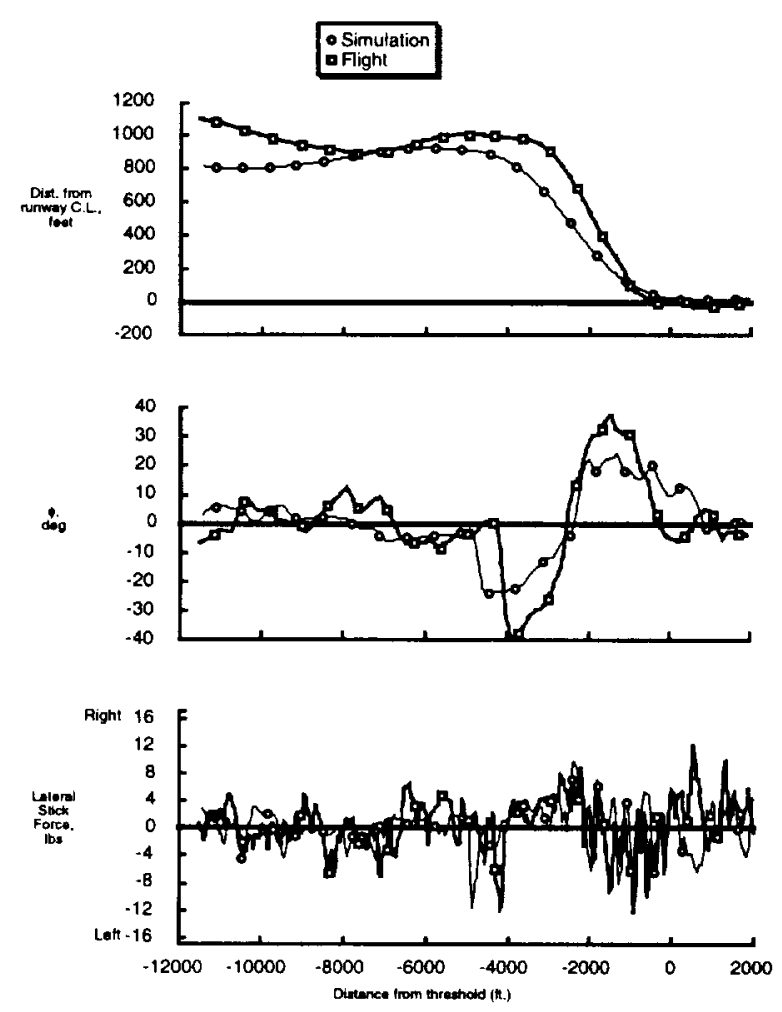

Figure 22.- Sidestep to landing, lateral performance, pilot A.
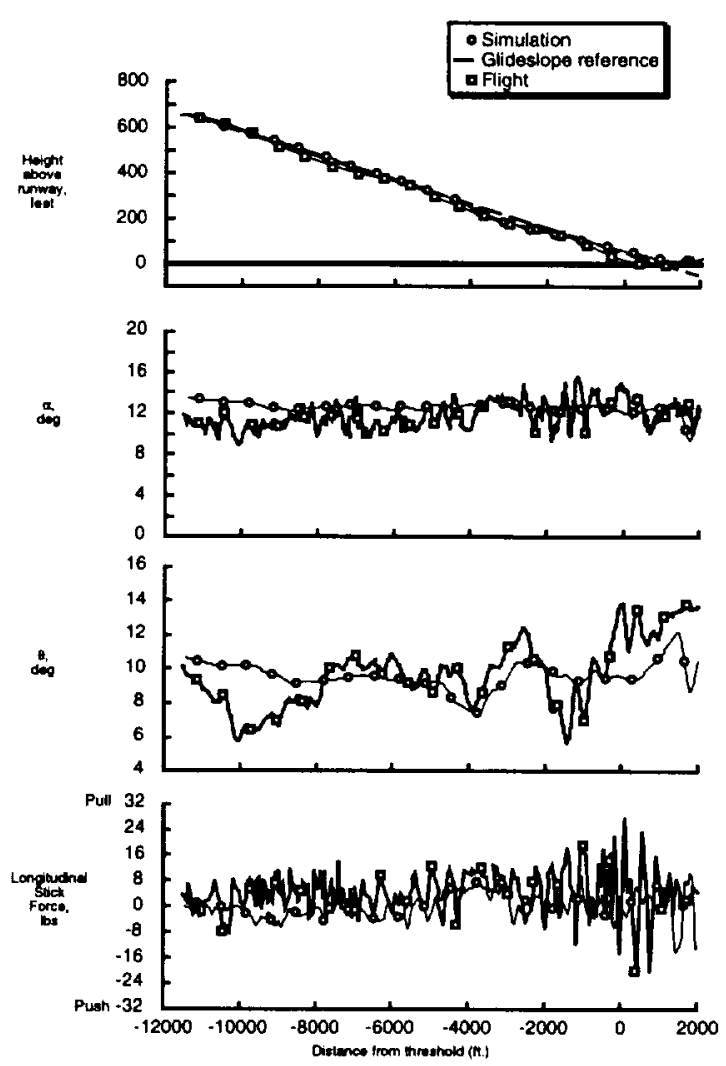

Figure 23.- Sidestep to landing, longitudinal performance, pillot A. 


\section{.}

